\title{
Platelets from schizophrenic patients bear autoimmune antibodies that inhibit dopamine uptake
}

\author{
ABRAHAM KESSLER and MEIR SHINITZKY \\ Weizmann Institute of Science, Rehovot, Israel
}

\begin{abstract}
Platelet-associated antibodies (PAA) from schizophrenic patients and healthy individuals were determined by conventional enzyme immunoassay. The platelets of the schizophrenic patients were found to carry notably higher levels of PAA than were those of the healthy controls. PAA from the schizophrenics inhibited specifically the uptake of dopamine (DA) by platelets. The DA uptake by normal platelets could be reduced to a level similar to that observed in platelets of schizophrenics upon binding of PAA from schizophrenics. Serotonin uptake was virtually unaffected by these antibodies. The Vmax value of dopamine uptake by platelets of schizophrenics was similar to that for normal platelets treated with PAA of schizophrenics, as well as that for normal untreated platelets. However, the $\mathrm{Km}$ values of the uptake were higher in the platelets from schizophrenics and normals treated with PAA from schizophrenics than in the untreated platelets of normals. PAA from schizophrenics were found to bind to rat brain P2m membranes and to interfere with the binding of the dopamine receptor ligands $\left[{ }^{3} \mathrm{H}\right]$-dopamine and $\left[{ }^{3} \mathrm{H}\right]-$ spiperone. These results suggest that blood platelets may function as a peripheral epitope for the formation of PAA, which, when reaching the brain, may react with the dopamine receptor and elicit mental disorder.
\end{abstract}

Schizophrenia is a severe and prevalent mental disorder with a well-documented symptomatology, but despite extensive investigations over the past decades, the etiology of this disease remains a conundrum. The looming issue is the overwhelming complexity of schizophrenia, and even today, the debate about whether schizophrenia represents a distinct mental disorder or is just one component of a spectrum of different mental diseases compiled under the same generic name is still unresolved (Fudenberg, Whitten, Merker, \& Farmatti, 1983; Tsuang, Lyons, \& Faraone, 1990). Multiple biological changes have been ascribed to this syndrome (American Psychiatric Association, 1987; Crow, 1980; Klein, Gittelman, Quitkin, \& Rifkin, 1980; Liddle, 1987), but there is still a basic disagreement about their relevance to its etiology.

A growing body of evidence indicates that some neurological diseases might be associated with immunological dysfunctions (Carnegie \& MacKay, 1975; DeLisi \& Crow, 1986; Fudenberg et al., 1983; Jankovic, 1985). Despite a lack of consistent experimental evidence (Amkraut, Solomon, Allansmith, McClellan, \& Rappaport, 1973; Kirchbach, Fisher, Eike, \& Kornhuber, 1987; Knight, 1984; Pandey, Gupta, \& Chaturvedi, 1981; Whit-

This research was supported by a grant from the MINERVA Foundation, Munich, Germany. A.K. is presently affiliated with the Rekanati Center for Rehabilitation, National Institute for the Rehabilitation of Brain Injuries, 89 Yizhak Sadeh St., 67228 Tel-Aviv, Israel. Correspondence concerning this article should be addressedd to $M$. Shinitzky, Department of Membrane Research and Biophysics, Weizmann Institute of Science, 76100 Rehovot, Israel. tingham, Mackay, Jones, \& Davis, 1968), hypotheses concerning the involvement of autoimmune elements in schizophrenia have been discussed for decades (Baron, Stern, Anavi, \& Witz, 1977; DeLisi, King, \& Targum, 1984; DeLisi et al., 1981; Ganguli, Rabin, Kelly, Lyte, \& Ragu, 1987; Heath \& Krupp, 1967; Karpiak, Serokosz, \& Rappaport, 1976; Knight, 1984; Mueller-Eckhardt, Kayser, \& Mersch-Baumert, 1980; Pandey et al., 1981; Shinitzky et al., 1991; Teplizki, Sela, \& Shoenfeld, 1992). Such hypotheses have emerged from observations that antibodies from sera of some schizophrenic patients are able to react in vitro with brain tissue (DeLisi, Weber, \& Pert, 1985; Jankovic, 1984). Elevated levels of antibrain antibodies have also been found in the sera of patients with diseases such as Huntington's chorea (Husby et al., 1977), myasthenia gravis (Lefvert \& Pirskanen, 1977), and others (Cawley, James, Minard, \& Bryant, 1984; Greenlee \& Brashear, 1983; Trotter, Hendin, \& Osterland, 1976). However, for schizophrenia, the findings have been contradictory, and positive indications of the presence of such antibodies have been obtained in only about $25 \%$ of the patients tested. Of particular relevance is the biogenic amine hypothesis regarding schizophrenia (Carlsson, 1978; Carlton \& Manowitz, 1984; Meltzer \& Stahl, 1976; Seeman, 1987), which evolved from the observations that dopamine (DA) receptors are blocked by neuroleptic drugs (Hornykiewicz, 1963) and implied the involvement of DA-receptor autoantibodies (Abramsky \& Litvin, 1978; Knight, 1982).

The preponderance of evidence that links the psychological, nervous, and immune systems (Ader, Cohen, \& 
Felten, 1987; Hofstein, Segal, \& Samuel, 1980; Jankovic, 1984; Solomon, 1987) led us to reinvestigate the autoimmune hypothesis of schizophrenia (Shinitzky et al., 1991). If indeed specific autoimmune antibodies are involved in the pathogenesis of schizophrenia, the fact that the brain is well protected from its environment by the blood-brain barrier hints at the possibility that the epitope that induces the formation of such antibodies is actually located in the periphery. It has been reported that platelets from schizophrenic patients exhibit some abnormal activities (Boullin, Orr, \& Peters, 1978; Rotman, Munitz, Modai, Tjano, \& Wijsenbeck, 1980). In view of their apparent involvement in leucocyte activities (Markus et al., 1988) and the remarkable parallels in a number of properties of platelets with those found in the CNS (Gordon \& Overman, 1978; Omenn \& Smith, 1978; Pletcher, Affolter, Cesura, Erne, \& Mueller, 1984; Sneddon, 1973), we postulated that platelets could possibly serve as the peripheral trigger for an autoimmune reaction that eventually propagates to the CNS. This assumption would imply an existence of common antigen epitopes in circulating blood platelets and the brain. In our preliminary account, we reported on the existence of elevated levels of autoantibodies in human blood platelets of schizophrenic and demented patients (Shinitzky et al., 1991). In the present investigation, we studied their functional relevance to schizophrenia.

\section{METHOD}

\section{Patients and Control Subjects}

Blood samples were obtained from 46 schizophrenic patients hospitalized in the Abarbanel (Bat-Yam) and Geha (Petach Tikva) Mental Hospitals. The patients met DSM-III criteria (American Psychiatric Association, 1987) for the schizophrenic disorder, and they were all on neuroleptic drug regimens unless specified otherwise. Their mean age was 27 years (range, 18-42). Because of previous results (Shinitzky et al., 1991), no attempt was made to subdivide the patients according to treatment or stage of the disease. The number of patients included in each experiment will be given subsequently. No patient had any immunological or allergic disorder, and their laboratory tests were normal.

The control group consisted of 52 healthy volunteers with a mean age of 24 (range, 19-36). They had no present or past evidence of a psychiatric disorder and no family history of any mental or immunological diseases.

\section{Isolation and Purification of Platelet-Associated Antibodies}

Venous blood was drawn before breakfast into heparinized tubes and processed within $2 \mathrm{~h}$. To separate the platelets, the blood was centrifuged at $100 \mathrm{~g}$ for $5 \mathrm{~min}$ at room temperature. The plateletrich plasma (PRP) was collected, and the number of platelets were scored microscopically. We found that this manual scoring could avoid errors due to platelet aggregation and was highly reproducible. After platelet scoring, the PRP was centrifuged at $1,500 \mathrm{~g}$ for $10 \mathrm{~min}$ at $4^{\circ} \mathrm{C}$. The supernatant was discarded and the pellet was resuspended in its own remaining fluid and washed thrice with $2 \mathrm{ml}$ of phosphate-buffered saline (PBS). After the third washing, the surface-bound platelet antibodies were peeled off by suspending the platelets in $0.2 \mathrm{M}$ glycine-HCl buffer, $\mathrm{pH} 3$. After an incubation of $5 \mathrm{~min}$ at $37^{\circ} \mathrm{C}$, the suspension was centrifuged at $17,500 \mathrm{~g}$ for $10 \mathrm{~min}$, and the supernatant was neutralized with $\mathrm{K}_{2} \mathrm{HPO}_{4}$. The solubilized platelet-associated antibodies (PAA) were purified by an anti- human immunoglobulin (IgG) affinity column (Tucker, Begent, \& Hogg, 1978) composed of antihuman IgG coupled to $N$-hydroxysuccinimide agarose (Wilchek \& Miron, 1982). PBS was used as a loading and washing buffer, and $0.1 \mathrm{M}$ acetic acid (pH 2.2) was used for elution. In some instances, rabbit antihuman IgG and protein A were also employed for the affinity purification of PAA. The purified PAA were neutralized with $\mathrm{K}_{2} \mathrm{HPO}_{4}$ and then concentrated in Centricon 30. The same procedure was applied for the isolation and purification of PAA from healthy donors and schizophrenic patients. Purity was verified by gradient polyacrylamide gel electrophoresis $(5 \%-15 \%)$, which revealed one band at $150 \mathrm{~K}$ under nonreducing conditions and two bands at 25 and $50 \mathrm{~K}$ in the presence of $240 \mathrm{mM} \mathrm{1,4-dithiothreitol} \mathrm{as} \mathrm{reducing} \mathrm{agent.} \mathrm{No} \mathrm{other} \mathrm{bands}$ were detectable.

\section{Assay of PAA Levels}

The levels of PAA and their distribution relative to platelet number were determined by an enzyme-linked immunoassay (ELI) based on color development after reaction with antihuman IgG bound to horseradish peroxidase (Leporrier, Dighiero, Auzemery, \& Binet, 1979)

For the ELI procedure, $300 \mu \mathrm{l}$ of PRP were centrifuged, the pellet was resuspended in the remaining fluid, and $1 \mathrm{ml}$ of PBS was added. This step was repeated three times. Finally, the pellet was resuspended in $0.15 \mathrm{ml}$ of PBS containing antihuman IgG linked to horseradish peroxidase (Bio-Yeda, Rehovot) in a final dilution of 1:1,000 and incubated for $30 \mathrm{~min}$ at $37^{\circ} \mathrm{C}$. Then, after four washings with PBS at $4^{\circ} \mathrm{C}$, the platelet suspension was incubated with freshly prepared substrate reagent $(99 \mathrm{ml}$ of distilled water $+1 \mathrm{ml}$ of methanol containing $10 \mathrm{mg}$ of ortho-phenylenediamine $+0.1 \mathrm{ml}$ of $3 \% \mathrm{H}_{2} \mathrm{O}_{2}$ ) for $1 \mathrm{~h}$ at $37^{\circ} \mathrm{C}$. The reaction was terminated by adding $0.1 \mathrm{ml}$ of $6 \mathrm{~N}$ sulfuric acid, and the optical density (OD) was read at $480 \mathrm{~nm}$. After background substraction, the OD was calculated per $10^{8}$ platelets per milliliter. This procedure was highly reproducible $(p<.05)$ and was therefore routinely employed.

The absolute level of the bound antihuman IgG was evaluated with the aid of a calibration curve of OD versus antibody concentration carried out for each specific batch used. The level of PAA was assumed to be identical to the scored level of the bound second antibody, since the latter was presented in a large excess.

\section{Adsorption of PAA to Platelets}

Suspensions of platelets were incubated with PAA from schizophrenics or normals. The suspensions were first incubated for $10 \mathrm{~min}$ at room temperature $\left(-23^{\circ} \mathrm{C}\right)$ and subsequently for $5 \mathrm{~min}$ at $37^{\circ} \mathrm{C}$. After two washings with PBS, the absorbed antibodies were assayed by ELI.

\section{Uptake of Bioamines by Platelets}

Samples of $475 \mu \mathrm{l}$ in Eppendorf microtubes, adjusted to $10^{8}$ platelets per milliliter with autologous platelet poor plasma, were preincubated for $5 \mathrm{~min}$ at $37^{\circ} \mathrm{C}$ for temperature equilibration. Uptake assays were conducted by a slight modification of a published method (Rotman et al., 1980), which was initiated by adding $25 \mu \mathrm{l}\left[{ }^{3} \mathrm{H}\right]-$ DA (specific activity, $17.5 \mathrm{Ci} / \mathrm{mmole}, \mathrm{NEN}$ ) or $\left[{ }^{3} \mathrm{H}\right]$-serotonin (specific activity, $15.2 \mathrm{Ci} / \mathrm{mmole}, \mathrm{NEN}$ ). Nonradioactive amines were added to give a specific activity of $1 \mathrm{mCi} / \mathrm{mmole}$. In the assays of uptake, the final concentrations of the amines ranged from 1 to $250 \mu \mathrm{M}$. Since the amine uptake was found to be practically linear with time for an incubation period of $20 \mathrm{~min}$, the uptake was allowed to continue for exactly $5 \mathrm{~min}$ and was terminated by transferral of the microtubes to ice water and then centrifuging them at $4^{\circ} \mathrm{C}$. The platelet pellet was resuspended in $1 \mathrm{ml}$ of ice-cold PBS and precipitated by centrifugation. The last step was repeated three times when only background counts could be detected in the supernatant. The pellet was suspended in $60 \mu \mathrm{l}$ of $1 \% \mathrm{NaOH}$, incubated overnight at room temperature, and then counted for radioactivity. Control values were obtained by adding tritium-labeled bioamines 
at equivalent concentrations to PRP samples kept on ice, treated otherwise as above.

\section{P2m Synaptosomal Membrane Preparations \\ From Human and Rat Brains}

Slices of human brains were obtained from a local pathological institute (Abu Kabir). Two-month-old Sprague-Dawley rats were obtained from the Animal Breeding Center of The Weizmann Institute of Science. The rats were sacrificed by rapid cervical dislocation. The brain was immediately taken out and dissected or placed in liquid nitrogen and stored at $-70^{\circ} \mathrm{C}$ for not more than 1 month before dissection.

Membranes from the human and rat brains were prepared according to Morgan et al. (1971), with minor modifications. All solutions used for membrane preparation contained protease inhibitors (EDTA, $20 \mathrm{mM}$; benzarnidine, $15 \mu \mathrm{g} / \mathrm{ml}$; phenylmethanesulfonylfluoride, $1 \mathrm{mM}$; leupeptin, $5 \mu \mathrm{g} / \mathrm{ml}$; and soybean trypsin inhibitor, $5 \mu \mathrm{g} / \mathrm{ml}$ ). All homogenation steps were carried out in an ice bath. The brain parts were cut into small pieces, gently homogenized in a glass/Teflon homogenizer and centrifuged at $1,000 \mathrm{~g}$ for $5 \mathrm{~min}$. The pellet was dispersed in $0.32 \mathrm{M}$ sucrose solution and centrifuged. The membrane vesicles in the combined supernatants were spun down at $20,000 \mathrm{~g}$ for $10 \mathrm{~min}$. The resulting pellet was resuspended in $0.32 \mathrm{M}$ sucrose, layered onto a gradient consisting of $4 \%$ Ficoll, $6 \%$ Ficoll, and $13 \%$ Ficoll $(w / v)$ in $0.32 \mathrm{M}$ sucrose and centrifuged for $45 \mathrm{~min}$ at $63,000 \mathrm{~g}$. The synaptosomal fraction (P2m membranes) was collected at the $6 \%-13 \%$ interface. This fraction was diluted with 4 volumes of $0.32 \mathrm{M}$ sucrose, and the synaptosomes were pelleted at $50,000 \mathrm{~g}$ for $20 \mathrm{~min}$. The yield of this fraction varied in the range of 8-14 $\mathrm{mg}$ per gram of wet weight and was essentially devoid of red blood cells and mitochondrial contamination.

\section{Ligand Binding to P2m Pretreated With Purified PAA}

Aliquots of $300 \mu \mathrm{l}$ of membrane preparation $(1 \mathrm{mg} / \mathrm{ml}$ protein) were preincubated with $20 \mu \mathrm{l}$ of PAA solution $(100 \mu \mathrm{g} / \mathrm{ml})$ for $20 \mathrm{~min}$ at room temperature. In the control samples, buffer was added to the membranes instead of PAA. After the termination of the preincubation time and washing of the excess PAA, the binding reaction was initiated by adding $\left[{ }^{3} \mathrm{H}\right]$-spiperone $(317 \mathrm{Ci} / \mathrm{mmole}$, NEN) and $\left[{ }^{3} \mathrm{H}\right]-D A(17.5 \mathrm{Ci} / \mathrm{mmole})$ to a final concentration of $10 \mu \mathrm{M}$, and the incubation was continued for $15 \mathrm{~min}$ at room temperature. Thereafter, bound ligand was separated from free ligand by rapid filtration through a Whatman glass filter (934-AH). The adhered membranes were then washed three times with ice-cold Tris buffer. The filters were dried, and the radioactivity was counted. Nonspecific binding was measured in the presence of $1 \mu \mathrm{M}$ mianserine and $1 \mu \mathrm{M}$ haloperidol.

\section{Data Analysis}

Statistical evaluation of the data and curve fitting were carried out with a Macintosh II computer.

\section{RESULTS}

The scoring of PAA in samples from normals $(n=52)$ and schizophrenics $(n=43)$ is presented in Figure 1. As shown, normal platelets carried an average level of $65 \mathrm{ng}$ of PAA per $10^{8}$ platelets, whereas platelets from schizophrenic patients carried an average of $123 \mathrm{ng}$ of PAA per $10^{8}$ platelets. At the time of blood drawing, most of the schizophrenics had received neuroleptic drugs for over 3 months. Five patients had received haloperidol for 2 days. Eight patients were newly admitted to the hospital and were drug free. Four were outpatients who had been drug free for over 3 months. All other patients were

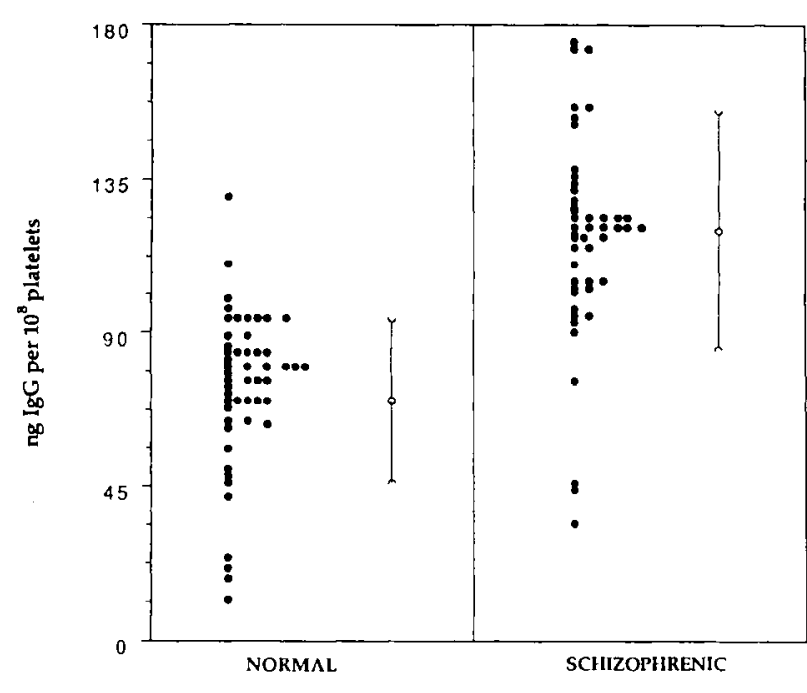

Figure 1. Scattergram of membrane-bound autoantibodies on platelets from control subjects and schizophrenic patients. The sample groups were composed of 52 bealthy controls and 43 schizophrenic patients. Each sample was assayed in quadruplicate by enzyme-linked immunoassay. The data are represented as $\mathrm{ng}$ IgG bound to $10^{8}$ platelets $(p \leq .001)$.

chronically treated with various neuroleptics. However, irrespectively of drug treatment, the blood platelets of the schizophrenics were found to carry a significantly higher level of surface-bound autoantibodies (Figure 1) than were the healthy controls $(p<.001)$, in agreement with our previous study (Shinitzky et al., 1991).

As indicated above, no significant effect of neuroleptics on the level of PAA in schizophrenics was noticed. In a separate pilot screening, we determined PAA in 5 newly diagnosed schizophrenic cases at the day of the outburst of the disease. The PAA values obtained for these cases were $70,90,94,180$, and $216 \mathrm{ng}$ of PAA per $10^{8}$ platelets. The average of these values (130 ng of PA per $10^{8}$ platelets) and their distribution comply well with the general profile of PAA in schizophrenia presented in Figure 1.

To obtain a preliminary comparison of the distribution of PAA among schizophrenic $(n=46)$ and healthy $(n=42)$ populations, crude PAA samples were scored and divided into five groups of PAA levels: 0-22, 23-45, $46-94,95-150$, and $151-210 \mathrm{ng}$ per $10^{8}$ platelets. As shown in Figure 2, above a level of about $75 \mathrm{ng}$ of PAA per $10^{8}$ platelets, $48 \%$ of the diseased population carried high levels of PAA, whereas only $17 \%$ of the healthy controls did so. Consequently, we compared PAA levels after the antibodies had been purified by affinity chromatography. As demonstrated by the number of false negative and false positive results, a similar but more pronounced difference between the schizophrenic and healthy individuals became apparent. In this case too, platelets from schizophrenic patients were found to carry significantly higher levels of surface-associated antibodies $\left(122 \pm 22 \mathrm{ng} / 10^{8}\right.$ platelets) than were the platelets from the healthy controls $\left(69 \pm 31 \mathrm{ng} / 10^{8}\right.$ platelets $)(p<$ 


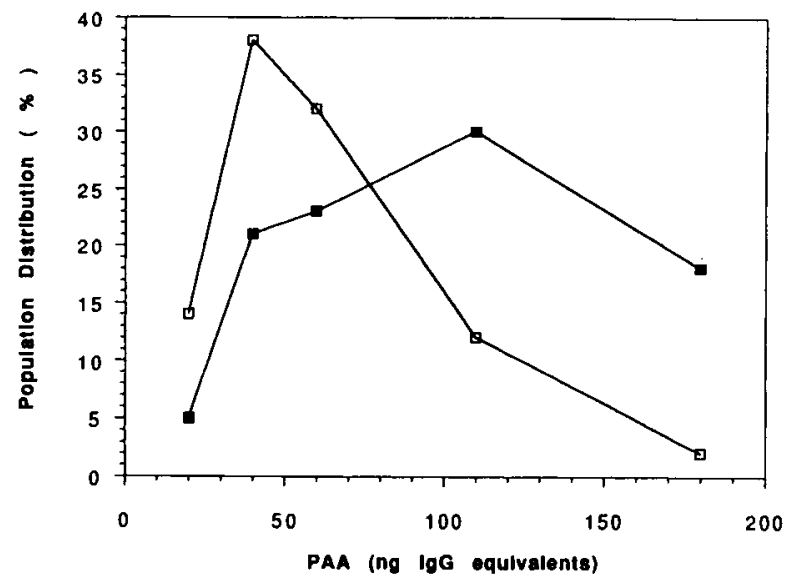

Figure 2. Average distribution of platelet-associated antibodies (PAA) among healthy $(n=42)$ and schizophrenic $(n=46)$ populations. The data of PAA are represented as $\mathrm{ng}$ IgG equivalents per $10^{8}$ platelets. Open squares, normals; filled squares, schizophrenics.

$.001)$. If we assume a cutoff point of $95 \mathrm{ng}$ per $10^{8}$ platelets, $13 \%$ of the patients ( 6 out of 46 ) were false negative, whereas $10 \%$ of the controls ( 4 out of 42 ) were false positive.

If one plots the number of platelets against respective levels of PAA, an inverse relationship between both variables becomes evident (Figure 3): the higher the platelet count, the lower the level of PAA. At high platelet counts, the levels of PAA reached values close to zero. For blood platelets of normal individuals, the recorded values were in a narrow range and no significant correlation between platelet number and level of PAA could be drawn (data not shown).

Blood platelets take up different neurotransmitters like DA, 5-hydroxytryptamine (serotonin, 5-HT) and norepinephrine. Postulating specificity for schizophrenic PAA, we have examined the uptake of $\left[{ }^{3} \mathrm{H}\right]-D A$ by platelets from schizophrenic patients (12 separate samples) and compared it with $\left[{ }^{3} \mathrm{H}\right]$-DA uptake by platelets from normals (13 samples). A consistent lower uptake of $75 \% \pm 5 \%$ of that of normals was observed, in agreement with previous reports (Rotman et al., 1980). Typical kinetic profiles of $\left[{ }^{3} \mathrm{H}\right]-D A$ uptake by platelets isolated from a normal individual and a schizophrenic patient are shown in Figure 4. Double reciprocal plots of the same data (Figure 5) indicated approximately the same Vmax value of $\left[{ }^{3} \mathrm{H}\right]-D A$ uptake of $40 \mathrm{pmole} / \mathrm{min} / 10^{8}$ platelets for both cases, and $\mathrm{Km}$ values of 23 and $41 \mu$ mole for the platelets from normals and schizophrenics, respectively. These values are consistent with competitive inhibition of DA uptake by PAA in platelets from schizophrenics.

Removal of PAA from platelets of schizophrenics (12 samples) was found to rectify almost completely the rate of DA uptake in all cases (data not shown). This observation supported the possibility that PAA are the causal factor in the observed inhibition of DA uptake. To gain further support for this possibility, we have interacted platelets from normals with PAA isolated from a pool of platelets from schizophrenics and examined their effect on $\left[{ }^{3} \mathrm{H}\right]-D A$ uptake. A distinct inhibition was observed. Typical kinetics of $\left[{ }^{3} \mathrm{H}\right]-D A$ uptake in a sample of platelets from a normal, before and after binding of PAA, are

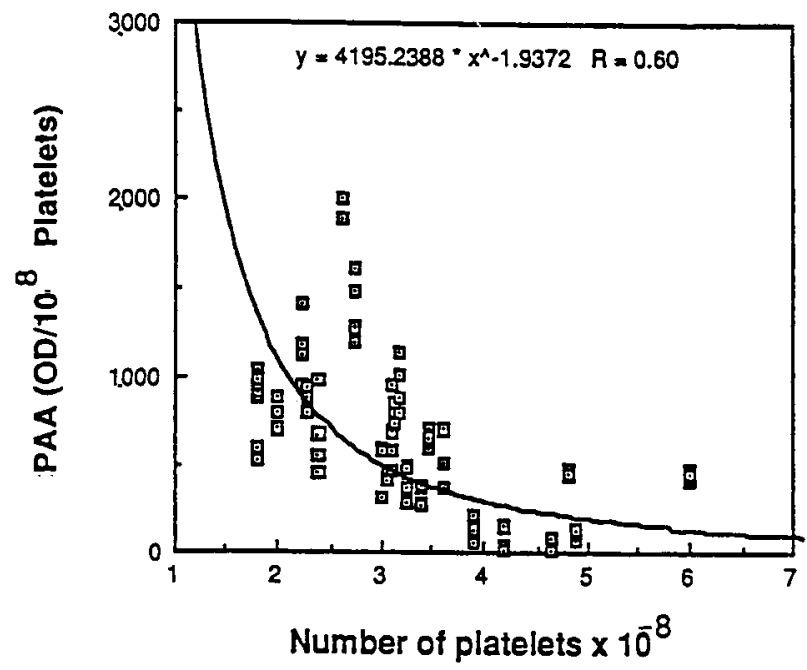

Figure 3. Correlation between number of circulating blood platelets per milliliter of plasma and the level of platelet-associated antibodies (PAA) in schizophrenics. Platelet-rich plasma from schizophrenics was prepared from 56 schizophrenic patients, and the number of platelets was scored. The level of PAA was examined by an enzyme-linked immunoassay procedure. Each dot represents the mean value of quadruplicate of each sample.

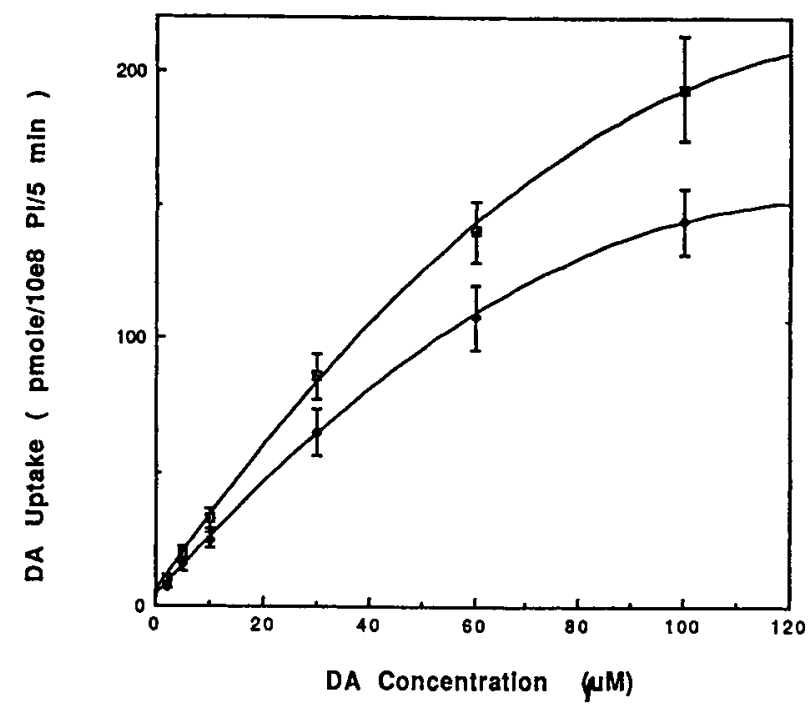

Figure 4. Uptake of $\left[{ }^{3} \mathbf{H}\right]-D A$ by $10^{8}$ platelets from normal (open squares) and schizophrenic (filled diamonds) individuals in $1 \mathrm{ml}$ after 5 min incubation with increasing amounts of $\left[{ }^{3} \mathrm{H}\right]-\mathrm{DA}$. Experiments were carried out in quintuplicate and the results are presented as mean $( \pm S D)$. 


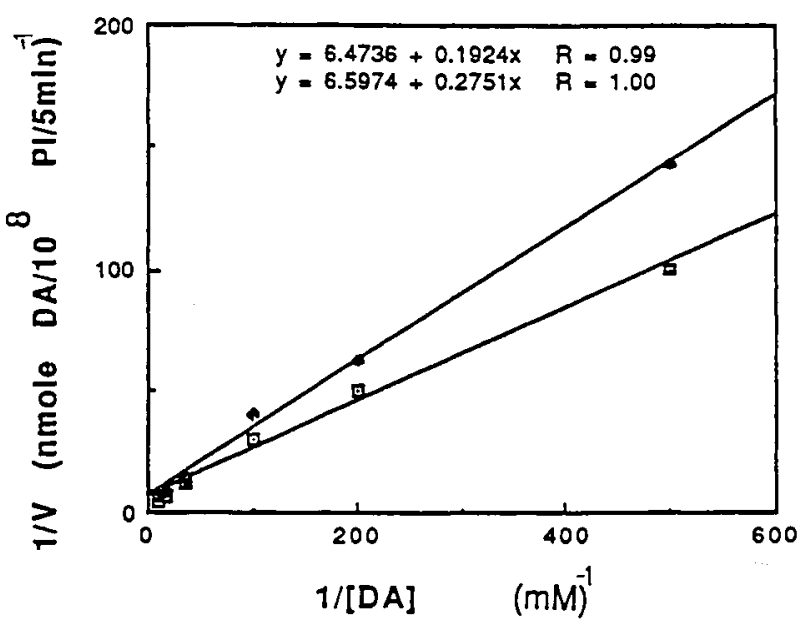

Figure 5. Double reciprocal presentation of the data shown in Figure 4.

shown in Figure 6. A double reciprocal plot analogous to Figure 5 is presented in Figure 7. The clear similarity between the data of Figures 4 and 6 indicates that the antigenic sites to which PAA binds are present on platelets from normals, at a level and in a functional vicinity of the DA carrier that are similar to the case for platelets from schizophrenics. The kinetic constants of the uptake of DA by platelets from schizophrenic patients, platelets from normals, and platelets from normals supplemented with PAA from schizophrenics are summarized in Table 1. The effect of PAA from schizophrenics on 5-HT uptake by platelets was only marginal and in most experiments was insignificant (not shown).

In another set of experiments, rat brain $\mathrm{P} 2 \mathrm{~m}$ membranes (whole brain minus cerebellum) were preincubated with schizophrenic PAA or buffer, in the presence and absence of mianserin and haloperidol. The results are presented in Table 2, indicating that PAA from schizophrenics inhibited, as in the platelets, the binding of DA ( $p \leq .01)$ and spiperone $(p \leq .05)$ to brain tissue. Schizophrenic PAA did not inhibit the binding of yohimbine to the human $\alpha_{2}$-adrenergic receptor (not shown).

\section{DISCUSSION}

Human platelets from normal individuals are known to carry IgG on their surface at a level of several fg per platelet (Kelton \& Denomme, 1982; Kunicki, Kristopeit, \& Aster, 1982; Morse, Giulani, \& Nussbaum, 1981). The nature of their association with the platelet surface has not yet been addressed and was just ascribed to a reaction with a putative $\mathrm{Fc}$ receptor (Pfueller, Weber, \& Luescher, 1977) and to nonspecific adherence. The Fc receptor on platelets, however, seems to bind specifically IgG aggregates, rather than monomers (King, McDermott, \& Schreiber, 1990).

In conformity with our previous publication (Shinitzky et al., 1991), the results presented here show that circulat- ing blood platelets, regardless of their origin (normal or schizophrenic), bear surface antibodies (PAA). Platelets from schizophrenics were found to carry a statistically higher level of PAA than were platelets from normals. The latter yielded average values of about $60-70 \mathrm{ng}$ of PAA per $10^{8}$ platelets. This value equals approximately 3,000 IgG molecules bound per platelet, which falls in the range of levels reported by others (Kelton et al., 1989; Luiken et al., 1972; Pfueller \& David, 1986). Platelets from schizophrenics were found to sustain a statistically higher level of PAA, reaching about $130 \mathrm{ng}$ of PAA per

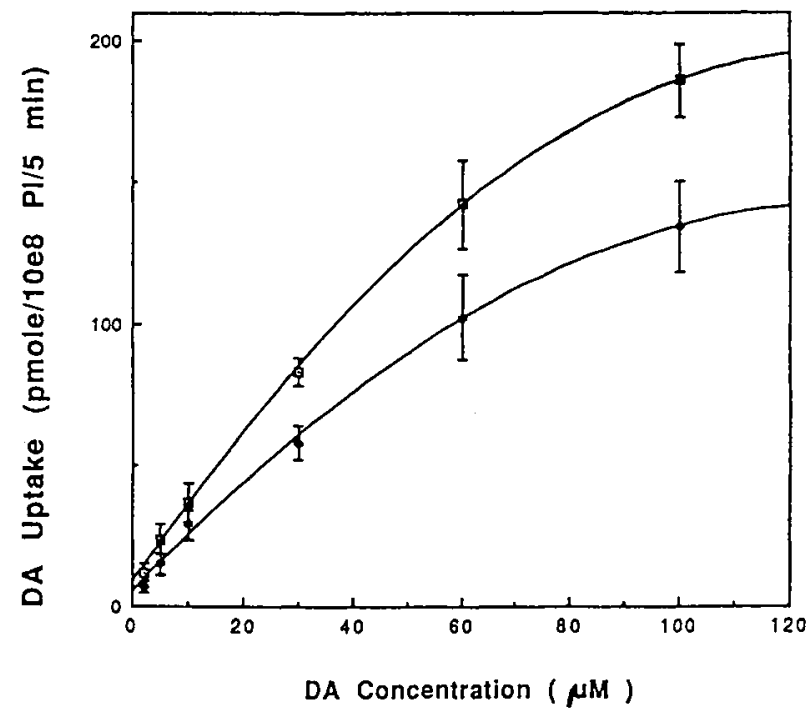

Figure 6. Uptake of [ $\left.{ }^{3} \mathrm{H}\right]-\mathrm{DA}$ by platelets from a normal subject before (open squares) and after (filled diamonds) the addition of $10 \mu \mathrm{g} / \mathrm{ml}$ platelet-associated antibodies from schizophrenics. Experimental details are as in Figure 4.

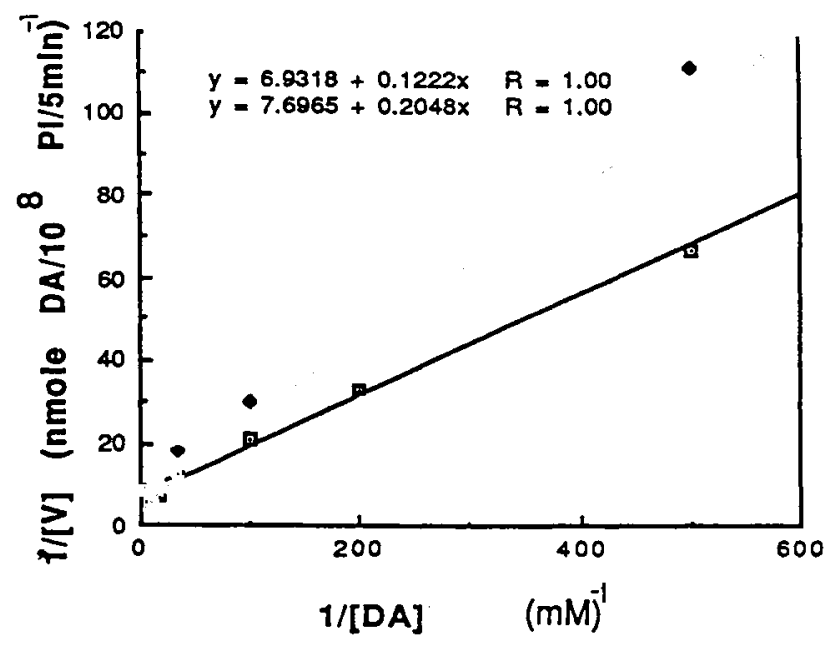

Figure 7. Double reciprocal presentation of the data shown in Figure 6. 
Table 1

Kinetic Constants of $\mathbf{B H}$ H-DA Uptake by Platelets From Normals, Platelets From Schizophrenics, and Platelets From Normals Supplemented With Platelet-Associated Antibodies (PAA) From Schizophrenics

\begin{tabular}{lcc}
\hline \multicolumn{1}{c}{ Platelets } & $\mathrm{Km}(\mathrm{mM})$ & $\begin{array}{c}\mathrm{Vmax} \\
\text { (pmole/10 } \mathrm{Pl} / 5 \mathrm{~min})\end{array}$ \\
\hline Normal & 29.7 & 154 \\
Schizophrenic & 41.7 & 151 \\
Normal + PAA & 41.2 & 149 \\
\hline
\end{tabular}

Table 2

Effect of Platelet-Associated Antibodies (PAA)

From Schizophrenics on Specific Binding of $\left[{ }^{3} \mathrm{H}\right]-\mathrm{DA}$ and Spiperone to Rat Brain P2m Membranes

\begin{tabular}{crr}
\hline Membranes $(2 \mathrm{mg} / \mathrm{ml})$ & {$\left[{ }^{3} \mathrm{H}\right]-\mathrm{DA}$} & {$\left[{ }^{3} \mathrm{H}\right]-$ Spiperone } \\
\hline P2m & $4,281 \pm 228$ & $6,849 \pm 713$ \\
P2m + PAA & $\dagger 2,756 \pm 202$ & ${ }^{* 4,081 \pm 582}$ \\
\hline
\end{tabular}

Note-P2m membranes (from whole rat brain minus cerebellum) were preincubated for $15 \mathrm{~min}$ with PAA. Binding of $\left[{ }^{3} \mathrm{H}\right]-D A$ and $\left[{ }^{3} \mathrm{H}\right]-$ spiperone was then assayed. Nonspecific binding was determined in the presence of haloperidol $(1 \mu \mathrm{M})$ and mianserine $(1 \mu \mathrm{M})$ and substrated from the total binding. ${ }^{*} p \leq .05 . \quad t p \leq .01$.

$10^{8}$ platelets, which equals roughly 5,000 molecules per platelet.

Although not all the patients of this study were on a neuroleptic drug regime, it stands to reason that the formation of PAA in schizophrenics is related to the disease rather than to a neuroleptic effect. High levels of PAA were found in drug-treated patients, drug-free patients, and patients free of drugs for over 3 months, with no significant difference. Data reported by Wong et al. (1986) appear to have resolved a similar long-standing dispute about whether increases in the number of dopamine receptors in the brains of schizophrenic patients are characteristic of the disease or are secondary to drug treatment. Positron emission tomography scans in living schizophrenic patients showed that, in both drug-treated and drug-free schizophrenics, the number of D2 dopamine receptors was significantly higher than it was in normals. The increase in receptors (as in the level of PAA), therefore, seems to be intrinsic to the disease and not the result of drug treatment. Hence, our finding that the PAA levels in platelets of schizophrenics are significantly elevated lends support to an autoimmune hypothesis of schizophrenia, though it presumably restricts the autoimmune component of the syndrome to a defined peripheral trigger localized at the platelet surface.

As shown in this study, PAA are prevalent in both normal and diseased individuals, though at different levels. Hence, if we assume that the normal persons were indeed healthy, it is suggestive to consider the eventuality that at least some features of platelet-directed autoimmunity may be benign as well as noxious. In other words, the difference between propitious autoimmunity and pernicious autoimmune schizophrenia occurs not entirely in the recognition of the platelet-associated self-antigens as such, but in the nature of the effector mechanisms that follow recognition. We are, therefore, led to assume that the immune system has the capacity to regulate autoimmunity and its biological consequences (Cohen, 1992).

PAA of schizophrenics were found to inhibit DA uptake by platelets (see Figures 6 and 7, and Table 1). The apparent $\mathrm{Kms}$ for the uptake of DA by normal, schizophrenic, and schizophrenic PAA-enriched normal platelets were 30,42 , and $41 \mu \mathrm{M}$, respectively. These values agree with the $\mathrm{Km}$ values reported for human and rat platelets by others (Gordon \& Overman, 1978; Lingjaerde \& Kildemo, 1981; Omenn \& Snith, 1978; Solomon, Spirt, \& Abrams, 1970). Thus, it is reasonable to assume that the lower affinity to DA encountered by the schizophrenic and normal platelets associated with schizophrenic PAA is probably imposed by binding schizophrenic PAA. The Vmax calculated from our data was around the narrow range of 30 pmole per $10^{8}$ platelets per min, irrespective of the source of the platelets. This value is very close to that published by Omenn and Smith (1978) but is somewhat different from that reported by others (Boullin et al., 1978; Gordon \& Overman, 1978). Different experimental conditions employed in the various studies could account for the disagreement in the reported Vmax's values. For instance, uptake of bioamines is markedly affected by different anticoagulants such as citric acid (Malmgren, 1984), EDTA (Lingjaerde \& Kildemo, 1981), and heparin (this study).

The distinct similarity between the data represented in Figures 4 and 6 suggests that the antigenic sites to which PAA binds are present also on platelets from normals, at a level similar to that of platelets from schizophrenics. The nature of the inhibitory effect of schizophrenic PAA on the uptake of DA-increase in the $\mathrm{Km}$ values without affecting Vmax-is analogous to cases of competitive inhibition in which the inhibitor is free in solution. In the present case, we can only state that the binding of schizophrenic PAA seems to reduce the affinity of DA to the DA transport system but does not affect the number of available binding sites or their turnover rate (Vmax unchanged). A plausible interpretation that complies with the present case would be that the binding site of PAA is topographically located near the transport site and by virtue of steric hindrance interferes with the binding of the surrounding DA molecules.

DA is believed to be taken up by platelets via the 5-HT transport system (Boullin et al., 1978; Gordon \& Overman, 1978). In our experiments, however, schizophrenic PAA did not inhibit significantly the uptake of 5-HT, though more experiments are required to verify this finding conclusively. If this nonsignificant effect of PAA on 5-HT uptake by platelets will be supported by further experimental evidence, we cannot then rule out the possibility of the existence of two different carrier systems in platelets for 5-HT and for DA, as suggested by Dean and Copolov (1989). The question whether the platelets can serve as a model system for the uptake of DA in the brain is still unclear. Despite the fact that platelets are considered by a number of researchers to be a less suitable model 
for DA uptake studies (Malmgren, 1984), they have been used as such for studies of disturbed dopaminergic functions in schizophrenia (Rotman et al., 1980) and other mental diseases (Barbeau \& Campanella, 1975). The uptakes of 5-HT (Lingjaerde, 1977) and the non-chloridedependent uptake of DA (Lingjaerde \& Kildemo, 1981) are both temperature-sensitive and carrier-dependent and might, therefore, be influenced by carrier-directed antiplatelet autoantibodies.

Schizophrenia is a brain syndrome, so antigens common to platelets and the brain would seem to be an a priori requirement for an autoimmune involvement of PAA in its etiology. The inhibitory effect of PAA of schizophrenics on the binding of DA to brain tissues (see Table 2) indicates that platelets and brain tissues do apparently contain a common antigen. Further support was obtained in preliminary experiments in which we could bind schizophrenic PAA to the solubilized $D_{2}$ receptor from brain. The detailed membrane structures that correspond to the PAA binding sites in the platelets and the brain are presently under investigation.

PAA and the classical neuroleptics administered to schizophrenics seem superficially to exert similar antagonistic effects on the dopaminergic system. Despite this similarity, it is conceptually difficult to extrapolate from the antagonistic action of the therapeutic agent on DA binding to the causal mechanisms of the disease, since pharmacological manipulations may produce changes that compensate for the disease without affecting the disorder itself. Furthermore, from a clinical standpoint, the time course of action of antipsychotic drugs differs notably from that of the disease. These drugs block DA binding rapidly, whereas the schizophrenic psychosis remits gradually over periods of weeks. This disparity suggests that blocking dopaminergic transmission may have secondary consequences for other neuronal systems that evolve gradually with time. Considering the time course of these two vectors, we hypothesize that binding of PAA in the brain of the schizophrenic corresponds to an initial decrease in the number of effective $\mathrm{D}_{2}$ dopamine receptors. Due to a delicate homeostasis mechanism in the latter system, a bouncing effect would be expected to occur, resulting in an increase in the number of $\mathrm{D}_{2}$ dopamine receptors, as found in schizophrenic patients by Wong et al. (1986). On the basis of our results, we tentatively conclude that an autoimune cascade is probably involved in at least a subset of patients with the schizophrenic syndrome. The blood platelet's DA transport system apparently functions as the peripheral trigger for the development of this cascade.

\section{REFERENCES}

Abramsky, O., LitVin, Y. (1978). Autoimmune response to dopamine-receptor as a possible mechanism in the pathogenesis of Parkinson's disease and schizophrenia. Perspectives in Biology \& Medicine, 22, 104-114.
Ader, R., Cohen, N., \& Felten, J. J. (1987). Brain, behavior and immunity. Brain, Behavior \& Immunity, 1, 1-6.

American Psychiatric Association (1987). Diagnostic and statistical manual of mental disorders-III. Washington, DC: Author.

Amkraut, A., Solomon, G. F., Allansmith, M., McClellan, G., \& RAPPAPORT, M. (1973). Immunoglobulins and improvement in acute schizophrenic reactions. Archives of General Psychiatry, 28, 673-677.

Barbeau, A., \& Campanella, G. (1975). Uptake and efflux of ${ }^{14} \mathrm{C}$ dopamine in platelets: Evidence for generalized defect in Parkinson's disease. Neurologica, 25, 1-9.

Baron, M., Stern, M., Anavi, R., Witz, I. P. (1977). Tissuebinding factor in schizophrenic sera: A clinical and genetic study. Biological Psychiatry, 12, 199-207.

Boullin, D. J., OrR, M. W., \& Peters, J. R. (1978). The platelet as a model for investigating the clinical efficacy of centrally acting drugs in schizophrenics. In G. Gaetano \& S. Garatini (Ed.), Platelets: A multidisciplinary approach (pp. 389-410). New York: Raven.

CarLsson, A. (1978). Antipsychiotic drugs, neurotransmitters and schizophrenia. American Journal of Psychiatry, 135, 164-173.

CARLTON, P. L., Manowttz, P. (1984). Dopamine and schizophrenia: An analysis of the theory. Neuroscience \& Biobehavioral Reviews, 8, 137-151.

CARnegie, P. R., \& MACKaY, I. R. (1975). Vulnerability of cell-surface receptors to autoimmune reactions. Lancet, 2, 684-686.

Cawley, L. P., James, V. L., Minard, B. J., \& Bryant, S. A. (1984). Antibodies to Purkinje cells and peripheral nerve in opoclonia. Lancet, 21, 509-510.

COHEN, I. R. (1992). The cognitive principle challenges clonal selection. Immunology Today, 13, 441-444.

Crow, T. J. (1980). Molecular pathology of schizophrenia: More than one disease process? British Medical Joumal, 280, 66-68.

DeAN, B., \& Copolov, D. L. (1989). Dopamine uptake by platelets is selective, temperature dependent and not influenced by the dopamine$\mathrm{D}_{1}$ or dopamine- $\mathrm{D}_{2}$ receptor. Life Sciences, 45, 401-411.

DELISI, L. E., \& Crow, T. J. (1986). Is schizophrenia a viral or immunological disorder? Psychiatric Clinics of North America, 9, 115-132.

DeLiSI, L. E., KING, A. K., \& TARGUM, S. (1984). Serum immunoglobulin concentration in patients admitted to an acute psychiatric inpatient service. British Journal of Psychiatry, 145, 661-664.

DeLisı, L. E., Weber, R. J., \& Pert, C. B. (1985). Are there antibodies against brain in sera from schizophrenic patients? Biological Psychiatry, 20, 94-119.

DeLisi, L. E., Weinberger, D. R., Neckars, L. M., Potkin, S., ShilING, D. J., \& WATT, R. J. (1981). Quantitative determination of immunoglobulins in CSF and plasma of chronic schizophrenic patients. British Joumal of Psychiatry, 139, 513-518.

FudenberG, H. H., Whitten, H. D., Merler, E., \& Farmati, 0. (1983). Is schizophrenia an autoimmunologic receptor disorder? Medical Hypotheses, 12, 85-93.

Ganguli, R., Rabin, B. S., Kelly, R. H., Lyte, M., \& Ragu, U. (1987). Clinical and laboratory evidence of autoimmunity in acute schizophrenia. Annals of the New York Academy of Sciences, 496, 676-690.

GoRdon, J. L., \& Overman, H. J. (1978). Hydroxytryptamine and dopamine transport by rat and human blood platelets. British Journal of Pharmacology, 62, 219-226.

Greenlee, G. E., \& Brashear, H. R. (1983). Antibodies to cerebellar Purkinje cells in patients with paraneoplastic cerebellar degeneration and ovian carcinoma. Annals of Neurology, 14, 609-613.

HEATH, R. G., \& KRUPP, I. M. (1967). Schizophrenia as an immunologic disorder: 1. Demonstration of antibrain globulins by fluorescent antibody techniques. Archives of General Psychiatry, 16, 1-9.

Hofstein, R., Segal, M., \& Samuel, D. (1980). Antibodies to synaptosomal membranes of rat hippocampus and caudate nucleus: Immunological and behavioral characteristics. Experimental Neurology, 70, 307-320.

HoRNYKIEWICZ, O. (1963). Die topische Lokalisation und das Verhalten von Noradrenalin und Dopamine in der substantia Nigra des normalen 
und parkinsonkranken Menschen. Klinische Wochenschrift, 75, 309-312.

Husby, G., Li, L., Davis, L. E., Wedege, E., Kokmen, E., \& WILLIAMS-JR., R. C. (1977). Antibodies to human caudate nucleus in Huntington's chorea. Journal of Clinical Investigation, 59, 922-932.

JANKOVIC, B. D. (1984). From immunoneurology to immunopsychiatry: Neuromodulating activity of antibrain antibodies. International Review of Neurobiology, 26, 249-314.

JANKOVIC, B. D. (1985). Neural tissue hypersensitivity. Journal of Immunology, 135, 853-857.

Karpiak, S. I., SERokosz, M., \& RaPPAPORT, M. (1976). Effects of antisera to $S-100$ protein and to synaptic membrane fraction on maze performance and EEG. Brain Research, 102, 313-321.

Kelton, J. G., Denomme, G. (1982). The quantitation of plateletassociated IgG on cohorts of platelets separated from healthy individuals by buoyant density centrifugation. Blood, 60, 136-139.

Kelton, J. G., Murphy, W. G., Lucarelu, A., GarVey-Willams, J., Santos, A., Meyer, R., \& Powers, P. (1989). A prospective comparison of four techniques for measuring platelet associated IgG. British Journal of Haematology, 71, 97-105.

King, M., MCDermott, P., \& SChreiber, A. D. (1990). Characterization of the $\mathrm{Fc}_{\gamma}$ receptor on human platelets. Cellular Immunology, 128, 462-479.

Kirchbach, A., Fisher, V., Eike, G., \& Kornhuber, H. H. (1987). Failure to detect dopamine receptor IgG autoantibodies in sera of schizophrenic patients. Journal of Neural Transmission, 70, 175-179.

Klein, D. F., Gittelman, R., Quitkin, F., \& Rifkin, F. (1980). Diagnosis and drug treatment of psychiatric disorders: Adults and children. Baltimore: Williams \& Wilkins.

KNIGHT, J. G. (1982). Dopamine receptor stimulating antibodies: A possible cause of schizophrenia. Lancet, 13, 1073-1076.

KNIGHT, J. G. (1984). Is schizophrenia an autoimmune disease? A review. Methods \& Findings in Experimental \& Clinical Pharmacology, 6, 395-411.

Kunicki, T. J., KRISTOPEIT, S. M., \& AsteR, R. H. (1982). Direct quantitation of platelet-associated IgG by electroimmunoassay. Blood, 60, 54-58.

Lefvert, A. K., \& Pirskanen, R. (1977). Acetylcholine-receptor antibodies in cerebrospinal fluid of patients with myasthenia gravis. Lancet, 13, 351-352.

Leporrier, M., Dighiero, G., Auzemery, M., \& Binet, J. L. (1979). Detection and quantification of platelet-bound antibodies with immunoperoxidase. British Journal of Haematology, 42, 605-611.

LIDDLE, P. F. (1987). The symptoms of chronic schizophrenia: A reexamination of the positive-negative dichotomy. British Journal of Psychiatry, 151, 145-151.

LiNGJAERDE, $O$. (1977). Platelet uptake and storage of serotonin. In E. W. Essan (Ed.), Serotonin in health and disease (pp. 129-199). New York: Spectrum.

LiNGJAERDE, O., \& KILDEMo, O. (1981). Dopamine uptake in platelets: Two different low affinity saturable mechanisms. Agents \& Actions, 11, 410-416.

Luiken, G. A., McMillan, R., Lightsey, A. L., Gordon, P., Zevely, S., Shulman, I., Gribble, T. J., \& Longmine, R. L. (1972). Platelet associated IgG in immune thrombocytopenia purpura. Blood, 50, 317-325.

Malmgren, R. (1984). Platelets and biogenic amines: 1. Platelets are poor investigative models for dopamine re-uptake. Psychopharmacology, 84, 480-485.

Markus, A. J., Salier, L. B., Ullman, H. L., Islama, T., BroekMAN, M. J., FALCK, J. R., FISChER, S., \& VoN-SCHACKY, C. (1988). Platelet-neutrophil interactions. Journal of Biological Chemistry, 263, 2223-2229.

Meltzer, H., Stahl, S. M. (1976). The dopamine hypothesis of schizophrenia. Schizophrenia Bulletin, 2, 19-76.

Morgan, J. G., Wolfe, L. S., Mandel, P., \& Gombes, G. (1971). Isolation of plasma membranes from rat brain. Biochimica Biophysica Acta, 241, 737-751.

Morse, B. S., GiUlani, D., \& Nussbaum, M. (1981). Quantitation of platelet-associated IgG by radial immunodiffusion. Blood, 57, 809-811.

Mueller-Eckhardt, C., Kayser, W., \& Mersch-Baumert, M. M. (1980). Clinical significance of platelet-asociated IgG: A study on 298 patients with various disorders. British Journal of Haematology, 46, 123-131

OmenN, G. S., \& Smith, L. T. (1978). A common uptake system for serotonin and dopamine in human platelets. Journal of Clinical Investigation, 58, 235-240.

Pandey, R. S., Gupta, A. K., \& Chaturvedi, V. C. (1981). Autoimmune model of schizophrenia with special reference to anti-brain antibodies. Biological Psychiatry, 16, 1123-1136.

Pfueller, S. L., \& DAvid, R. (1986). Liveration of surface and internal platelet associated IgG (PA-IgG) during platelet activation. British Journal of Haematology, 63, 785-794.

Pfueller, S. L., Weber, S., \&uescher, E. F. (1977). Studies of the mechanism of the human platelet reaction induced by immunologic stimuli. Journal of Immunology, 118, 514-524.

Pletcher, A., Affolter, H., Cesura, M., Erne, E., \& Mueller, K. (1984). Blood platelets as models for neurons: Similarities of the 5hydroxytryptamine systems. In H. G. Schlossberger, W. Kochen, B. Linzen, \& H. Steinhart (Eds.), Progress in tryptophan and serotonin research (pp. 231-239). Berlin: De Gruyter.

Rotman, A., Munitz, H., Modai, J., Tuano, S., \& WiJsenbeck, H. (1980). Comparative uptake study of serotonin, dopamine and norepinephrine by platelets of acute schizophrenic patients. Psychological Review, 3, 239-246.

SEEmaN, P. (1987). Dopamine receptors and the dopamine hypothesis of schizophrenia. Synapse, 1, 133-152.

Shinitzky, M., Deckman, M., Kessler, A., Sirota, P., Rabbs, A., \& Elizur, A. (1991). Platelet autoantibodies in dementia and schizophrenia-possible implication for mental disorders. Annals of the New York Academy of Sciences, 621, 205-217.

SNEDDON, M. (1973). Blood platelets as a model for monoamine containing neurons. In G. A. Kerkut \& J. W. Phillips (Eds.), Progress in neurobiology (pp. 151-192). New York: Pergamon.

Solomon, G. F. (1987). Psychoneuroimmunology: Interactions between central nervous system and immune systems. Journal of Neuroscience Research, 18, 1-9.

Solomon, H. M., SpIRT, N. M., Abrams, W. B. (1970). The accumulation and metabolism of dopamine by the human platelet. Clinical Pharmacology \& Therapeutics, 11, 838-845.

TePlizki, H. A., Sela, B., \& ShOenfeld, Y. (1992). Autoantibodies to brain and polynucleotides in patients with schizophrenia: A puzzle. Immunologic Research, 11, 66-73.

Trotter, G. L., Hendin, B. A., \& Osterland, K. (1976). Cerebellar degeneration with Hodgkin disease. Archives of Neurology, 33, 660-661.

TsuANG, M. T., Lyons, M. J., \& FARAONE, S. V. (1990). Heterogeneity of schizophrenia: Conceptual models and analytic strategies. British Journal of Psychiatry, 156, 17-26.

TuCKer, D. F., Begent, R. H. J., HoGG, N. M. (1978). Characterization of immune complexes in serum by adsorption staphylococcal protein. American Journal of Immunology, 121, 1644-1659.

Whittingham, S., Mackay, I. R., Jones, I. H., \& Davis, B. (1968). Absence of brain antibodies in patients with schizophrenia. British Medical Journal, 1, 347-348.

WILCHEK, M., \& MIRON, T. (1982). Immobilization of enzymes and affinity ligands onto agarose via stable and uncharged carbamate linkages. Biochemistry International, 4, 629-635.

Wong, D. F., Wagner, H. N., Tune, L. E., Dannals, R. F., Pearlson, G. D., Links, J. M., Tamminga, C. A., Bronssolle, E. P., Ravert, H. T., Wilson, A. A., Toung, T., Malat, J., Williams, J. A., OTuama, L. A., Snyder, S. H., Kuhar, M. J., \& GJedde, A. (1986). Positron emission tomography reveals elevated $D_{2}$ dopamine receptors in drug-naive schizophrenics. Science, 234, 1558-1563.

(Manuscript received January 4, 1993; revision accepted for publication May 4, 1993.) 